\title{
As Consequências dos Acordos de Livre Comércio Sobre o Setor de Lácteos no Brasil
}

Augusto Mussi Alvim¹

Resumo: Este artigo analisa os principais efeitos dos acordos de livre comércio sobre o setor de lácteos no Brasil. Utiliza-se um modelo de equilíbrio parcial formulado como um Problema de Complementaridade Mista (MCP na sigla em inglês) para avaliar mudanças (ganhos e perdas potenciais) em termos de produção, consumo e comércio em cada cenário. Tal modelo considera multirregiões e multiprodutos, o que permite analisar os impactos de políticas de livre comércio para diferentes regiões e diversos produtos lácteos.

Palavras-chave: Problema de Complementaridade Mista (MCP), modelos de equilíbrio parcial, setor de lácteos, análise multirregional e multiproduto.

Abstract: This paper discusses the main effects of free trade agreements on the dairy sector in Brazil. A partial equilibrium model formulated as a Mixed Complementary Problem (MCP) is used to provide some numerical examples of changes (potential gain and losses) in terms of production, trade and welfare in each scenario. This model also considers a multiregional and a multi-product dimension, which permits to analyze the impact of trade liberalization upon different regions and diverse processed dairy products.

Key-words: Mixed Complementary Problem (MCP), partial equilibrium models, dairy sector, and multiregional and multi-product analysis.

Classificação JEL: Q 17, C61.

1 Doutor em Economia. Professor do Departamento de Ciências Econômicas e do Programa de Pós-Graduação em Economia (PPGE) da Pontifícia Universidade Católica do Rio Grande do Sul (PUCRS), Porto Alegre (RS). E-mail: augusto.alvim@pucrs.br. 


\section{Introdução}

O comércio internacional de produtos agrícolas tem se tornado cada vez mais complexo em função das barreiras tarifárias e não-tarifárias aplicadas e dos subsídios concedidos pelos países desenvolvidos. É o caso do setor de lácteos, onde há expressivo número de tarifas ad valorem e quotas tarifárias que podem variar conforme o tipo e a especificação do produto, a região de origem e os acordos comerciais pré-existentes.

As tarifas ad valorem são as principais barreiras comerciais adotadas pelos países em desenvolvimento, a exemplo dos do Mercosul. Por outro lado, os países desenvolvidos, que mantêm maior nível de proteção de mercado, utilizam quotas tarifárias e concedem subsídios à produção e à exportação de produtos lácteos.

O protecionismo no mercado internacional de lácteos resultante dessas práticas, associado à perecibilidade do produto, faz com que apenas $7 \%$ da produção de leite (equivalente leite) seja exportada. Por sua vez, o reduzido comércio de derivados de leite está atrelado às fortes oscilações nos preços internacionais ao longo dos anos, o que reflete principalmente nos países com menores níveis de proteção (em desenvolvimento).

Ao mesmo, tempo, segundo Nicholson e Bishop (2004), a adoção de novas tecnologias no setor de lácteos tem permitido uma série de avanços, entre eles a separação dos diversos componentes do leite (gordura, proteína, lactose e outros sólidos), tornando o comércio internacional desses produtos economicamente viável. A maior competitividade resultante dessa mudança tecnológica impõe uma pressão política sobre as decisões comerciais, englobando práticas protecionistas e a definição dos preços mínimos ao produtor nos países desenvolvidos.

Nesse sentido, optou-se pelo uso de modelos de equilíbrio parcial, que possibilitam um maior detalhamento e avaliação das práticas comerciais no setor de lácteos. Entre os estudos já desenvolvidos que utilizaram tal modelagem citam-se os de Nagurney, Nicholson e Bishop (1996), Alvim (2003), Alvim e Waquil $(2004,2005)$ e Bender Filho e Alvim (2008). No presente trabalho, porém, a metodologia permite incluir os componentes dos produtos lácteos nos diversos níveis da cadeia, tornando possível definir diferentes tarifas, quotas tarifárias e barreiras não-tarifárias para cada produto, além de estimar preçossombra para os componentes do leite.

É nesse contexto que são avaliados os possíveis efeitos de acordos de livre comércio regional e multilateral, envolvendo os países do Mercosul, sobre o setor de lácteos no Brasil. Para analisar esses impactos, utiliza-se um modelo de equilíbrio parcial formulado como um Problema de Complementaridade Mista (PCM) que considera multirregiões (dimensão espacial) e multiprodutos (dimensão vertical). 
São simulados três cenários de livre comércio: (a) um acordo de livre comércio multilateral com a remoção das barreiras tarifárias e dos subsídios; (b) um acordo entre Mercosul e União Europeia (UE) com a remoção das barreiras tarifárias; e (c) um acordo de livre comércio entre os países do Mercosul, Estados Unidos e Canadá, com a remoção das barreiras tarifárias.

O presente trabalho está organizado em quatro seções, incluindo esta introdução. A segunda seção detalha a metodologia de estudo, apresentando o modelo de equilíbrio parcial formulado como um PCM e os cenários alternativos. Na sequência vêm os resultados, com análises do cenário-base e dos cenários alternativos que consideram a simulação de novos acordos de livre comércio. E, por fim, são apresentadas as principais conclusões deste trabalho.

\section{O Problema de Complementaridade Mista (PCM)}

O modelo de programação descrito nesta seção é formulado como um Problema de Complementaridade Mista (PCM), conforme proposto por Thore (1992), Waquil (1995, 2000), Rutheford (1995), Bishop, Nicholson e Pratt (2001), Alvim (2003), Nicholson e Bishop (2004) e Alvim e Waquil (2004, 2005).

O PCM define um equilíbrio espacial e vertical, relacionando a produção de leite e derivados nas diversas regiões (relação espacial) para as diferentes indústrias processadoras de leite (relação vertical). Para cada produto analisado, se assume que os preços, quantidades ofertadas e demandadas e os fluxos comerciais sejam variáveis endógenas. Outros fatores, como tecnologia, custos de processamento, composição dos produtos, preferências e crescimento populacional são variáveis exógenas ao modelo.

O modelo leva em consideração as funções de oferta de leite fluído (nível de produtor) e demanda por leite em pó (integral e desnatado), queijo, manteiga e outros derivados do leite (nível de consumidor) em cada região. Juntamente com os custos de transporte entre regiões e a presença de barreiras ao comércio, é possível estimar as quantidades produzidas e consumidas, os fluxos comerciais e os preços em equilíbrio. Com esses dados, pode-se também calcular os níveis de bem-estar-medidos pelo excedente do produtor (EP) e o excedente do consumidor (EC) -, bem como as variações ocorridas a partir de diferentes cenários simulados, permitindo a avaliação dos ganhos ou perdas em cada situação.

O PCM consiste em um sistema de equações simultâneas (lineares ou não), apresentado na forma de desigualdades, as quais são derivadas a partir das funções de oferta e demanda dos produtos considerados em cada uma das regiões analisadas. O modelo é equivalente às condições de primeira ordem (Kuhn-Tucker) do problema de maximização da função Net Social Payoff ${ }^{2}$

2 Samuelson (1952) mostrou que o equilíbrio de mercado pode ser alcançado a partir da maximização da função de Net Social Payoff (NSP), obtida com a soma dos excedentes dos produtores e dos consumidores. 
(NSP); condições estas que são necessárias e suficientes para atingir um ponto máximo do valor da função NSP, o que, por sua vez, implica na obtenção do equilíbrio em todos os mercados e em todas as regiões. Entretanto, o PCM tem a vantagem de permitir a incorporação de tarifas, quotas tarifárias e subsídios com mais facilidade ao modelo. Engloba, ainda, algumas variáveis relevantes na avaliação do setor de processamento de leite, entre elas os diferentes custos de processamento entre as regiões, as diferenças em termos de composição do produto in natura e derivados (percentual de gordura, proteína, lactose e sólidos) e os diversos níveis de proteção de mercados em cada patamar de produção.

A diferença na proporção de componentes do leite entre as regiões faz com que exista uma distinção também entre o preço recebido pelo produto in natura, tornando explícito, no modelo, que as indústrias processadoras veem o leite in natura como uma combinação de componentes (gordura, proteína, lactose e outros sólidos). Esses componentes são transformados em leite em pó (integral e desnatado), queijo, manteiga e outros lácteos. O grupo "outros lácteos" é expresso em equivalente leite, agregando todos os derivados do leite não incluídos no estudo.

O Quadro 1 apresenta a notação utilizada e a definição das variáveis para a implantação do modelo. O conjunto das equações corresponde ao PCM e representa as condições que permitem obter os preços, as quantidades produzidas e consumidas e os fluxos comerciais entre as regióes, levando em conta as tarifas, quotas tarifárias e os subsídios fixados nos mercados.

Quadro 1. Variáveis utilizadas no modelo de programação.

\begin{tabular}{|c|c|}
\hline$q_{1}^{s}$ & Quantidade ofertada na região i (variável endógena). \\
\hline $\mathrm{q}_{\mathrm{j}, \mathrm{k}, \mathrm{m}}^{\mathrm{c}}$ & $\begin{array}{l}\text { Quantidade de } \mathrm{m} \text { componentes recebidos pela indústria } \mathrm{k} \text { da região i. O } \\
\text { produto chega à indústria na forma de leite fluído (variável endógena). }\end{array}$ \\
\hline $\mathrm{q}_{\mathrm{i}, \mathrm{k}, \mathrm{m}}^{\mathrm{pc}}$ & $\begin{array}{l}\text { Quantidade de } m \text { componentes dos produtos derivados processados na } \\
\text { indústria } k \text {, na região i (variável endógena). }\end{array}$ \\
\hline $\mathrm{q}_{\mathrm{i}, \mathrm{k}}^{\mathrm{prd}}$ & $\begin{array}{l}\text { Quantidade de produtos derivados produzidos na indústria } k \text {, na região } \\
\text { i. A variável inclui os custos de processamento para cada unidade produ- } \\
\text { zida (variável endógena). }\end{array}$ \\
\hline $\mathrm{q}_{\mathrm{j}, \mathrm{k}}^{\mathrm{d}}$ & $\begin{array}{l}\text { Quantidade demandada de } \mathrm{k} \text { derivados do leite na região } \mathrm{j} \text { (variável en- } \\
\text { dógena). }\end{array}$ \\
\hline $\mathrm{X}_{\mathrm{i}, \mathrm{j}, \mathrm{k}}$ & $\begin{array}{l}\text { Fluxo de comércio de leite fluído entre a região i e a indústria k, na região } \\
\text { j (variável endógena). }\end{array}$ \\
\hline $\mathrm{Xf}_{\mathrm{i}, \mathrm{j}, \mathrm{k}, \mathrm{l}}$ & $\begin{array}{l}\text { Fluxo de comércio de derivados do leite entre a indústria k na região i e os } \\
\text { consumidores na região j (variável endógena). }\end{array}$ \\
\hline $\mathrm{t}_{\mathrm{i}, \mathrm{j}}^{\mathrm{L}}$ & $\begin{array}{l}\text { Custo de transporte de leite fluído da região i para a região j (variável } \\
\text { exógena). }\end{array}$ \\
\hline $\mathrm{t}_{\mathrm{i}, \mathrm{j}, \mathrm{k}}^{\mathrm{D}}$ & $\begin{array}{l}\text { Custo de transporte de derivados do leite da região i para a região j de } \mathrm{k} \\
\text { derivados do leite (variável exógena). }\end{array}$ \\
\hline
\end{tabular}




\begin{tabular}{|c|l|}
\hline $\operatorname{tar}_{\mathrm{i}, \mathrm{j}}^{\mathrm{L}}$ & $\begin{array}{l}\text { Tarifa imposta sobre o leite fluído originário da região i na região j (vari- } \\
\text { ável exógena). }\end{array}$ \\
\hline $\operatorname{tar}_{\mathrm{i}, \mathrm{j}, \mathrm{k}}^{\mathrm{D}}$ & $\begin{array}{l}\text { Tarifa imposta sobre os derivados do leite originário da região i na região } \\
\mathrm{j} \text { (variável exógena). }\end{array}$ \\
\hline $\mathrm{cp}_{\mathrm{i}, \mathrm{k}}$ & $\begin{array}{l}\text { Custo de processamento de k indústrias de derivados do leite em i regiões } \\
\text { (variável exógena). }\end{array}$ \\
\hline $\mathrm{sr}_{\mathrm{i}, \mathrm{m}}$ & Proporção de m componentes do leite fluído na região i (variável exógena). \\
\hline $\mathrm{sf}_{\mathrm{i}, \mathrm{k}, \mathrm{m}}$ & $\begin{array}{l}\text { Proporção de m componentes dos derivados do leite na indústria } \mathrm{k}, \mathrm{da} \\
\text { região i (variável exógena). }\end{array}$ \\
\hline$\varphi_{\mathrm{i}}$ & $\begin{array}{l}\text { Multiplicador de Lagrange: preço-sombra do leite fluído na região produ- } \\
\text { tora i (variável endógena). }\end{array}$ \\
\hline$\lambda_{\mathrm{j}, \mathrm{k}, \mathrm{m}}$ & $\begin{array}{l}\text { Multiplicador de Lagrange: preço-sombra de m componentes do leite flu- } \\
\text { ído recebido pela indústria k na região j (variável endógena). }\end{array}$ \\
\hline$\sigma_{\mathrm{i}, \mathrm{k}, \mathrm{m}}$ & $\begin{array}{l}\text { Multiplicador de Lagrange: preço-sombra de m componentes de deriva- } \\
\text { dos do leite processados na indústria } \mathrm{k}, \text { da região i (variável endógena). }\end{array}$ \\
\hline$\pi_{\mathrm{i}, \mathrm{k}}$ & $\begin{array}{l}\text { Multiplicador de Lagrange: preço-sombra de produtos derivados do leite } \\
\text { produzidos em k plantas, na região i (variável endógena). }\end{array}$ \\
\hline$\delta_{\mathrm{j}, \mathrm{k}}$ & $\begin{array}{l}\text { Multiplicador de Lagrange: preço-sombra na região consumidora j (vari- } \\
\text { ável endógena). }\end{array}$ \\
\hline$\alpha_{\mathrm{i}}$ & Termo constante da função de oferta (variável exógena). \\
\hline$\varepsilon_{\mathrm{i}}$ & Elasticidade preço da função de oferta (variável exógena). \\
\hline$\beta_{\mathrm{i}}$ & Termo constante da função de demanda (variável exógena). \\
\hline$\mu_{\mathrm{i}}$ & Elasticidade preço da função de demanda (variável exógena). \\
\hline
\end{tabular}

Fonte: Organizado pelo autor.

As equações de (1) a (5) são fundamentais para delimitar os resultados do modelo. Junto com uma função objetivo apropriada, elas equivalem à formulação primal clássica de Samuelson-Takayama-Judge do modelo de equilíbrio espacial e vertical. Já as equações de (6) a (11) correspondem à formulação dual clássica, aqui apresentada como um PCM.

Na primeira equação, observa-se que $\varphi_{i}$ é uma variável complementar à expressão que restringe a soma das exportações de leite in natura da i-ésima região ao total produzido na região i, representando o preço-sombra na região produtora i. Da mesma forma, a segunda equação apresenta uma variável $\lambda_{\mathrm{i}, \mathrm{k}, \mathrm{m}}$, complementar à expressão que restringe a quantidade de $\mathrm{m}$ componentes do leite in natura recebido pela k-ésima indústria, na região j; representa o preçosombra de m componentes do leite adquirido pela indústria.

A equação (3) assegura que a quantidade comercializada de componentes do leite com o consumidor final não exceda a quantidade processada na indústria. A variável $\sigma_{i, k, m}$ é complementar a essa expressão e representa o preço-sombra 
de m componentes de derivados do leite processados na indústria. Já a equação (4) permite que o modelo calcule a quantidade de m componentes nos derivados de leite processados pela indústria, sendo possível identificar o custo de processamento por unidade do produto final, equivalente ao preço-sombra $\pi_{\mathrm{i}, \mathrm{k}}$.

Na equação (5), $\delta_{\mathrm{j}, \mathrm{k}}$ é uma variável complementar à expressão que restringe a soma das importações de derivados de leite da j-ésima região ao total consumido na região j. Em outras palavras, a quantidade demandada de derivados de leite não pode ser maior que o volume comercializado.

Formulação do Problema de Complementaridade Mista:

$$
\begin{aligned}
& \varphi_{\mathrm{i}} \geq 0,\left(\sum_{\mathrm{j}}^{\mathrm{J}} \sum_{\mathrm{k}}^{\mathrm{K}} \mathrm{X}_{\mathrm{i}, \mathrm{j}, \mathrm{k}}-\mathrm{q}_{\mathrm{i}}^{\mathrm{s}}\right) \cdot \varphi_{\mathrm{i}}=0, \forall \mathrm{i}, \mathrm{k} \\
& \lambda_{\mathrm{j}, \mathrm{m}, \mathrm{m}} \geq 0,\left(\mathrm{q}_{\mathrm{j}, \mathrm{m}, \mathrm{m}}^{\mathrm{c}}-\sum_{\mathrm{i}}^{\mathrm{I}}\left(\mathrm{sr}_{\mathrm{j}, \mathrm{m}} \cdot \mathrm{X}_{\mathrm{i}, \mathrm{j}, \mathrm{k}}\right) \cdot \lambda_{\mathrm{j}, \mathrm{k,m}}=0, \forall \mathrm{j}, \mathrm{k}, \mathrm{m}\right. \\
& \sigma_{\mathrm{i}, \mathrm{k,m}} \geq 0,\left(\sum_{\mathrm{j}}^{\mathrm{J}} \sum_{\mathrm{l}}^{\mathrm{L}} \mathrm{Xf}_{\mathrm{i}, \mathrm{j}, \mathrm{k}, \mathrm{l}}-\mathrm{q}_{\mathrm{i}, \mathrm{k}, \mathrm{m}}^{\mathrm{prc}}\right) \cdot \sigma_{\mathrm{i}, \mathrm{k}, \mathrm{m}}=0, \forall \mathrm{i}, \mathrm{k}, \mathrm{m} \\
& \pi_{\mathrm{i}, \mathrm{k}} \geq 0,\left(\sum_{\mathrm{j}}^{\mathrm{J}} \sum_{\mathrm{k}}^{\mathrm{K}} \mathrm{Xf}_{\mathrm{i}, \mathrm{j}, \mathrm{k}, \mathrm{l}}-\mathrm{q}_{\mathrm{i}, \mathrm{k}}^{\mathrm{prd}}\right) \cdot \pi_{\mathrm{i}, \mathrm{k}}=0, \forall \mathrm{i}, \mathrm{k} \\
& \delta_{j, k} \geq 0,\left(\mathrm{q}_{\mathrm{j}, \mathrm{k}}^{\mathrm{d}}-\sum_{\mathrm{i}}^{\mathrm{I}} \sum_{1}^{\mathrm{L}} \mathrm{Xf}_{\mathrm{i}, \mathrm{j}, \mathrm{k}, \mathrm{l}}\right) \cdot \delta_{\mathrm{j}, \mathrm{k}}=0, \forall \mathrm{j}, \mathrm{k} \\
& \mathrm{q}_{\mathrm{i}}^{\mathrm{s}} \geq 0,\left(\left(\frac{\mathrm{q}_{\mathrm{i}}^{\mathrm{s}}}{\alpha_{\mathrm{i}}}\right)^{1 / \mathrm{s}_{\mathrm{i}}}-\varphi_{\mathrm{i}}\right) \cdot \mathrm{q}_{\mathrm{i}}^{\mathrm{s}}=0, \forall \mathrm{i} \\
& \mathrm{X}_{\mathrm{i}, \mathrm{j}, \mathrm{k}} \geq 0,\left(\left(\varphi_{\mathrm{i}}+\mathrm{t}_{\mathrm{i}, \mathrm{j}}^{\mathrm{L}} \cdot\left(1+\operatorname{tar}_{\mathrm{i}, \mathrm{j}}^{\mathrm{L}}\right)-\sum_{\mathrm{m}}^{\mathrm{M}}\left(\mathrm{sr}_{\mathrm{j}, \mathrm{m}} \cdot \lambda_{\mathrm{j}, \mathrm{k}, \mathrm{m}}\right)\right) \cdot \mathrm{X}_{\mathrm{i}, \mathrm{j}, \mathrm{k}}=0, \forall \mathrm{i}, \mathrm{j}, \mathrm{k}\right. \\
& \mathrm{q}_{\mathrm{i}, \mathrm{k}, \mathrm{m}}^{\mathrm{prc}} \geq 0,\left(\lambda_{\mathrm{j}, \mathrm{k}, \mathrm{m}}-\sigma_{\mathrm{i}, \mathrm{k}, \mathrm{m}}\right) \cdot \mathrm{q}_{\mathrm{i}, \mathrm{k}, \mathrm{m}}^{\mathrm{prc}}=0, \forall \mathrm{i}, \mathrm{k}, \mathrm{m} \\
& \mathrm{q}_{\mathrm{i}, \mathrm{k}}^{\mathrm{prd}} \geq 0,\left(\mathrm{cp}_{\mathrm{i}, \mathrm{k}}-\pi_{\mathrm{i}, \mathrm{k}}\right) \cdot \mathrm{q}_{\mathrm{i}, \mathrm{k}}^{\mathrm{prd}}=0, \forall \mathrm{i}, \mathrm{k} \\
& \mathrm{q}_{\mathrm{j}, \mathrm{k}}^{\mathrm{d}} \geq 0,\left(\delta_{\mathrm{j}, \mathrm{k}}-\left(\frac{\mathrm{q}_{\mathrm{j}, \mathrm{k}}^{\mathrm{j}}}{\beta_{\mathrm{j}, \mathrm{k}}}\right)^{1 / \mu, \mathrm{j}, \mathrm{k}}\right) \cdot \mathrm{q}_{\mathrm{j}, \mathrm{k}}^{\mathrm{d}}=0, \forall \mathrm{i}, \mathrm{j}, \mathrm{k} \\
& \mathrm{Xf}_{\mathrm{i}, \mathrm{k}, \mathrm{l}} \geq 0,\left(\left(\left(\sum_{\mathrm{m}}^{\mathrm{M}} \mathrm{sf}_{\mathrm{i}, \mathrm{k}, \mathrm{m}} \cdot \sigma_{\mathrm{i}, \mathrm{k}, \mathrm{m}}\right)+\pi_{\mathrm{i}, \mathrm{k}}+\mathrm{t}_{\mathrm{i}, \mathrm{j}, \mathrm{k}}^{\mathrm{D}}\right)\left(1+\operatorname{tar}_{\mathrm{i}, \mathrm{j}, \mathrm{k}}^{\mathrm{D}}\right)-\delta_{\mathrm{j}, \mathrm{k}}\right) \cdot \mathrm{Xf}_{\mathrm{i}, \mathrm{k}, \mathrm{l}, \mathrm{l}}=0, \forall \mathrm{i}, \mathrm{j}, \mathrm{k}, 1
\end{aligned}
$$

Para a equação (6), quando a quantidade ofertada for maior ou igual a zero, o preço que os produtores de leite estão interessados em vender o leite in natura deverá ser maior ou igual ao preço de mercado. Já a equação (7) define as condições para que exista comercialização de leite entre produtores e indústrias. Para que ocorra comércio $\mathrm{X}_{\mathrm{i}, \mathrm{j}, \mathrm{k}}$ o preço de mercado do produto in natura (mais 
o custo de transporte e tarifas) deverá ser igual ao preço do leite na indústria k. O preço na indústria é calculado com base na soma do valor dos componentes $\left(\lambda_{\mathrm{j}, \mathrm{k}, \mathrm{m}}\right)$, multiplicado pela composição do leite in natura recebido pela indústria.

A equação (8) representa o comportamento maximizador de lucros por parte das indústrias. Ou seja, quando a quantidade processada $\mathrm{q}_{\mathrm{i}, \mathrm{k}, \mathrm{m}}^{\mathrm{prc}}$ for maior que zero, os preços pagos pelos componentes presentes no leite in natura devem ser iguais aos preços de $\mathrm{m}$ componentes de derivados do leite processados na indústria $\mathrm{k}$.

A equação (9) determina que, quando a produção de $k$ indústrias $\mathrm{q}_{\mathrm{i}, \mathrm{k}}^{\mathrm{prd}}$ for maior que zero, o custo de processamento de cada unidade de produto deve ser igual ao preço-sombra associado a essa atividade de processamento. Caso contrário, quando o custo de processamento for maior que o preço-sombra, a quantidade produzida pela indústria será igual a zero.

A equação (10) estabelece que, se $\mathrm{q}_{\mathrm{j}, \mathrm{k}}^{\mathrm{d}}$ for maior ou igual a zero, o preço pago pelos consumidores pelos produtos derivados do leite deverá ser menor ou igual ao preço de mercado. Por fim, a equação (11) define as condições para que exista a comercialização de derivados de leite entre a indústria e os consumidores finais. Para que haja comércio $\left(\mathrm{Xf}_{\mathrm{i}, \mathrm{j}, \mathrm{k}, \mathrm{l}}\right)$, o preço de mercado dos derivados do leite na região i (mais custo de transporte e tarifas) deve ser igual ao preço da indústria na região j.

Os preços e as quantidades consumidas e ofertadas utilizados para a implantação do modelo foram obtidos por meio do banco de dados da OECD/ FAO. Considerou-se a média dos três últimos anos (de 2004 a 2006) visando à redução dos efeitos de alterações eventuais nos níveis das variáveis, causadas por choques ou mudanças abruptas na economia, por eventos climáticos ou por outros fatores que afetam, ocasionalmente, produção, consumo e preços (Quadro 2).

Para implantar o modelo, também são necessárias as elasticidades-preço de oferta e de demanda para definir as funções que participam das equações 6 e 10 . Os custos totais de transporte entre as regiões em estudo foram calculados com base no custo de transporte de uma tonelada de produtos a granel e refrigerados via marítima (US\$/milhas marítimas), obtido a partir de dados do Departamento de Agricultura dos Estados Unidos (USDA na sigla em inglês) e das distâncias (milhas marítimas) entre os países/regiões em análise (Quadro 2).

Como não existe uma tarifa comum em todos os países pertencentes às regiões definidas na área de estudo, foram utilizadas as tarifas médias dos países importadores dos blocos ou regiões escolhidos. Os subsídios e quotas tarifárias considerados no modelo foram aplicados exclusivamente para os Estados Unidos, Canadá e países da UE. 
Quadro 2. Variáveis utilizadas e suas respectivas fontes.

\begin{tabular}{|l|l|}
\hline \multicolumn{1}{|c|}{ Variáveis } & \multicolumn{1}{c|}{ Fontes } \\
\hline $\begin{array}{l}\text { Produção, consumo, exporta- } \\
\text { ção, importação e preços de } \\
\text { leite in natura e derivados. }\end{array}$ & $\begin{array}{l}\text { Organisation for Economic Co-operation and Devel- } \\
\text { opment and Food and Agriculture Organization of } \\
\text { United Nations (OECD/FAO, 2007). }\end{array}$ \\
\hline $\begin{array}{l}\text { Elasticidade de oferta e de } \\
\text { demanda. }\end{array}$ & $\begin{array}{l}\text { United State Department of Agriculture - Economic } \\
\text { Research Service (USDA-ERS, 2007); Food and Agri- } \\
\text { culture Policy Research Center (Fapri, 2007). }\end{array}$ \\
\hline Custo de transporte. & $\begin{array}{l}\text { World Bank (2002); United States Department of } \\
\text { Agriculture - Agriculture Marketing Services (USDA- } \\
\text { AMS, 2007). }\end{array}$ \\
\hline Custo de processamento. & Nicholson and Bishop (2004). \\
\hline $\begin{array}{l}\text { Composição dos produtos } \\
\text { (leite in natura e derivados). }\end{array}$ & $\begin{array}{l}\text { Embrapa Gado de Leite; Fonterra Co-operative Group } \\
\text { (Nova Zelândia); Composition of Food, USDA (USA). }\end{array}$ \\
\hline Coeficiente de transformação. & $\begin{array}{l}\text { Embrapa Gado de Leite; Fonterra Co-operative Group } \\
\text { (Nova Zelândia). }\end{array}$ \\
\hline & $\begin{array}{l}\text { United Nations Conference on Trade and development } \\
\text { (UNCTAD, 2007); United State Department of Agricul- } \\
\text { ture- Economic Research Service (USDA-ERS, 2007); } \\
\text { The International Customs Tariff Bureau (BITD, 2007). }\end{array}$ \\
Tarifas e quotas tarifárias. & $\begin{array}{l}\text { United State Department of Agriculture - Economic } \\
\text { Research Service (USDA-ERS, 2007). }\end{array}$ \\
\hline Subsídios. &
\end{tabular}

Fonte: Organizado pelo autor.

Quadro 3. Distribuição das regiões para a construção dos cenários.

\begin{tabular}{|c|l|}
\hline 1. & Argentina. \\
\hline 2. & Brasil. \\
\hline 3. & Uruguai. \\
\hline 4. & Canadá. \\
\hline 5. & Estados Unidos (EUA). \\
\hline 6. & $\begin{array}{l}\text { União Européia (UE) composta pelos quinze membros que já integravam o } \\
\text { bloco até 2004 (Alemanha, Áustria, Bélgica, Dinamarca, Espanha, Finlândia, } \\
\text { França, Grécia, Holanda, Irlanda, Itália, Luxemburgo, Portugal, Reino Unido e } \\
\text { Suécia) e os dez novos integrantes a partir de 2004 (Chipre, Eslováquia, Eslo- } \\
\text { vênia, Estônia, Hungria, Letônia, Lituânia, Malta, Polônia e República Tcheca). }\end{array}$ \\
\hline 7. & Austrália. \\
\hline 8. & Nova Zelândia (NZ). \\
\hline 9. & $\begin{array}{l}\text { Resto do mundo (RM): inclui todos os demais países, não pertencentes às } \\
\text { regiões ou blocos anteriormente citados. }\end{array}$ \\
\hline
\end{tabular}

Fonte: Organizado pelo autor. 
A área de estudo abrange o mercado mundial de leite e derivados, que inclui todos os países produtores, exportadores, importadores e consumidores do produto. Para viabilizar o processo de modelagem e a análise dos cenários de integração dos mercados, os países são agrupados em regiões. O critério para escolha leva em conta a relevância em termos de produção, importação e exportação, além de considerar as regiões com maior interesse comercial para o Brasil. Vale salientar que os países do Mercosul são analisados separadamente, a fim de identificar as mudanças em termos de produção e comércio nos diversos cenários. Entre os países e blocos relevantes no setor de lácteos, definiram-se nove regiões, conforme o Quadro 3.

Obtidos os resultados do modelo aplicado para o cenário-base, fez-se a calibragem para ajustar à situação atual. Na maior parte dos casos, a produção e o consumo observados no período não excederam em $5 \%$ os valores estimados e apresentados como cenário-base. Posteriormente, três cenários foram simulados, removendo barreiras ao comércio, a fim de verificar os impactos nas quantidades e níveis de bem-estar. Tais cenários são, respectivamente: um acordo de livre comércio multilateral; um acordo entre os países do Mercosul e da UE; e um acordo entre os países do Mercosul, Estados Unidos e Canadá (Quadro 4).

Quadro 4. Cenários considerados para a análise dos resultados.

\begin{tabular}{|c|l|}
\hline Cenário & \multicolumn{1}{c|}{ Definição } \\
\hline 1 & $\begin{array}{l}\text { Acordo multilateral - livre comércio entre todas as regiões, com a elimi- } \\
\text { nação das barreiras ao comércio e dos subsídios. }\end{array}$ \\
\hline 2 & $\begin{array}{l}\text { Acordo regional entre os países do Mercosul e da UE, com a remoção das } \\
\text { barreiras ao comércio. }\end{array}$ \\
\hline 3 & $\begin{array}{l}\text { Acordo de livre comércio entre os países do Mercosul, Estados Unidos e } \\
\text { Canadá, com a remoção das barreiras tarifárias. }\end{array}$ \\
\hline
\end{tabular}

Fonte: Organizado pelo autor.

Neste estudo, utilizaram-se os solvers Path, do Sistema Geral de Modelagem Algébrica (GAMS na sigla em inglês), desenvolvido em 1994, e o Miles - conforme sugestão de Rutherford (1995), principalmente para modelos complexos. Não houve diferença entre os resultados simulados em ambos os procedimentos.

Na próxima seção, são apresentados o cenário-base e as principais mudanças ocorridas nos diversos cenários alternativos em função da simulação de novos acordos de livre comércio. 


\section{Resultados}

\subsection{Cenário-base e calibragem do modelo}

Os modelos de programação matemática são geralmente validados através da checagem da solução do problema, comparando-a com a situação real. Nesta seção, analisa-se a forma com que os resultados obtidos no cenário-base (estimados) refletem os valores observados. Segundo Waquil (1995), em casos de não se obter resultados coerentes com os valores, o modelo deve ser reavaliado em termos de adequação dos coeficientes e da estrutura.

Para o presente estudo, quando analisadas variáveis como produção e consumo de leite e derivados, verifica-se que a diferença máxima entre os valores observados e estimados é de $10 \%$. Assim, o modelo pode ser validado no cenário-base, visto que os resultados no mundo real são condizentes com aqueles estimados pelo modelo.

Na Tabela 1, são apresentados os níveis de produção, consumo e participação de mercado em diversos segmentos do setor de lácteos no cenário-base. Os maiores produtores mundiais de leite in natura são os países da UE e os Estados Unidos, que produzem juntos 227.000 toneladas ao ano, representando $36 \%$ da produção global. Como observado na Figuras 1 e 2, além da importante participação no volume produzido, esses países possuem também grande peso no total consumido de leite e derivados. Os países da UE são os maiores consumidores de queijo (43\% do total mundial), seguidos pelos EUA, com $24 \%$. Destaca-se também o consumo de manteiga e de leite em pó desnatado nas mesmas regiões.

Figura 1. Produção e consumo de leite fluído nos países selecionados.

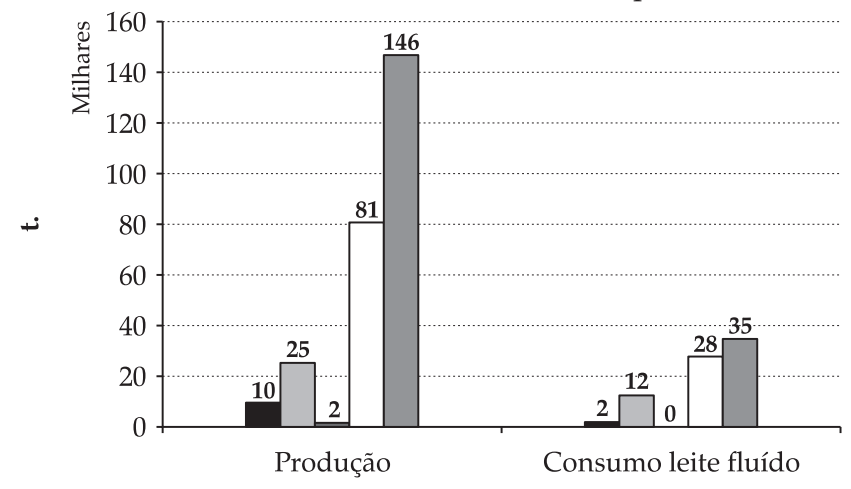

Argentina $\square$ Brasil $\square$ Uruguai $\square$ EUA $\square$ UE

Fonte: OCDE, 2008. 


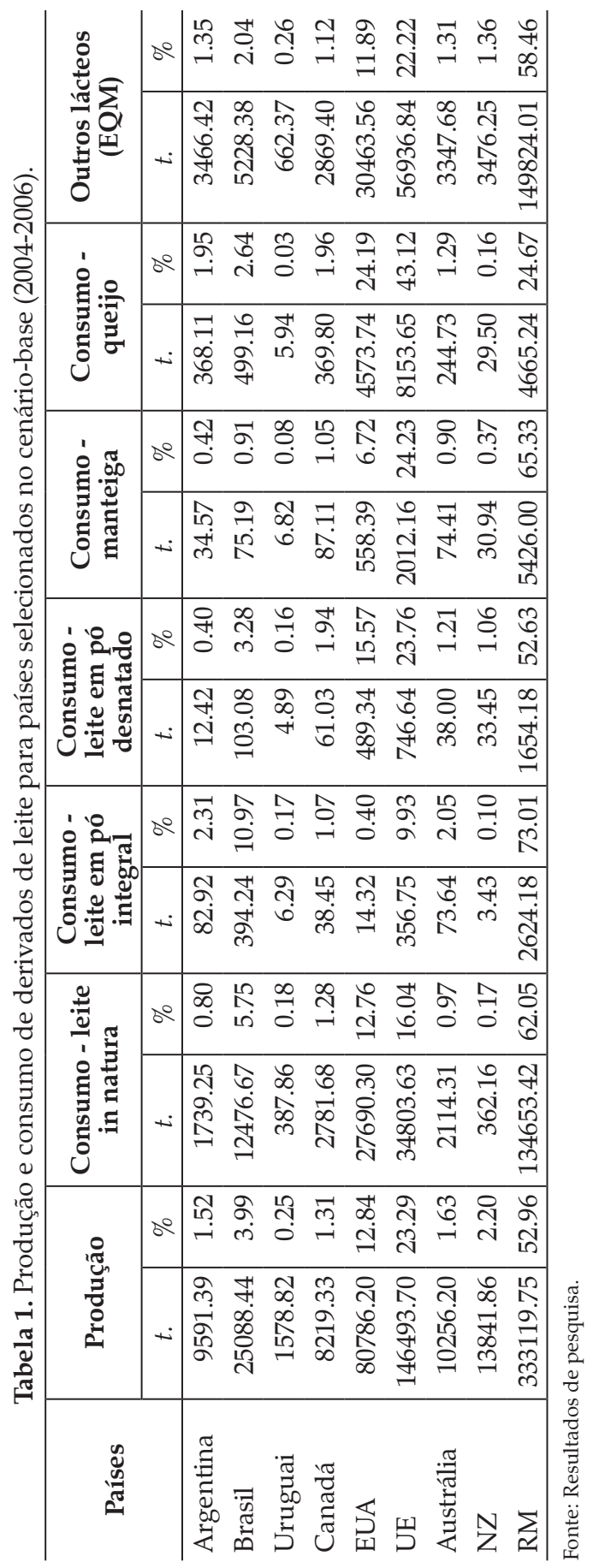


Figura 2. Consumo de leite em pó e desnatado, manteiga e queijo em países selecionados (toneladas), 2004-2006.

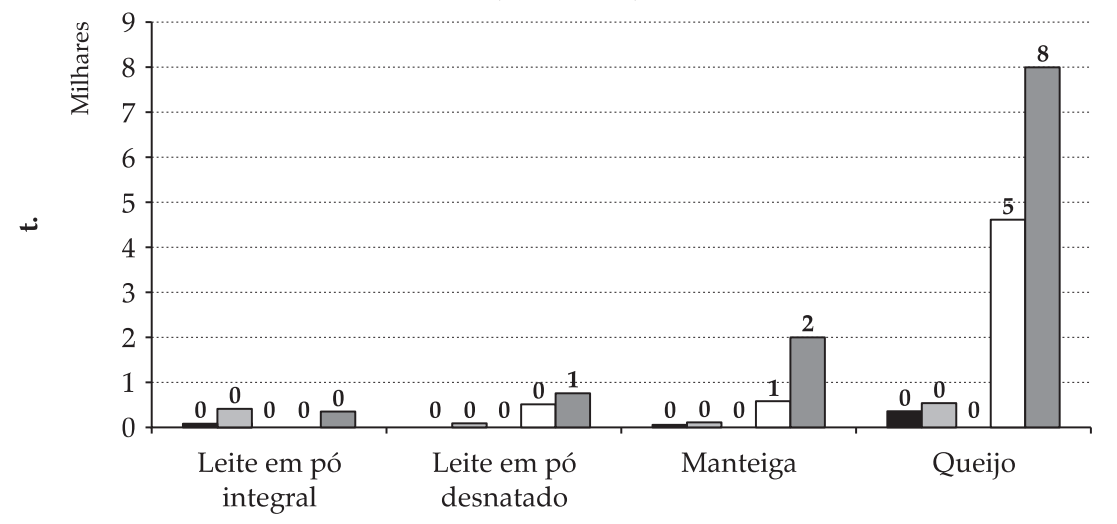

Argentina $\square$ Brasil $\square$ Uruguai $\square$ EUA $\quad \square$ UE

Fonte: OCDE, 2008.

Com uma participação menor na produção e no consumo de leite e derivados estão os países do Mercosul (Argentina, Brasil e Uruguai). O volume produzido nesses países representa apenas $6 \%$ do total mundial, no período analisado. No Brasil, a maior parte do consumo final ainda está associada ao leite in natura, correspondendo a $6 \%$ do total consumido do produto no mundo (Figura 1). Diferentemente das demais regiões analisadas, o consumo de leite em pó integral no Brasil representa parcela importante no total mundial, de $11 \%$.

Os países da Oceania, Austrália e Nova Zelândia, por sua vez, são os maiores exportadores líquidos de derivados do leite - com destaque para o leite em pó integral e desnatado -, embora tenham pequeno peso na produção e consumo mundiais.

Para cada um dos três grupos destacados, existem diferentes estratégias de inserção no mercado internacional. O primeiro utiliza-se de barreiras tarifárias e subsídios para manter a sua posição privilegiada. Como resultado, tem conseguido manter um nível de produção capaz de atender à demanda por derivados lácteos nas suas respectivas regiões. Ao mesmo tempo, porém, o excesso de oferta no mercado internacional, em decorrência desses subsídios e quotas tarifárias, acaba distorcendo os preços em função da comercialização de tais excedentes.

Os países do Mercosul, por sua vez, não subsidiam a produção e as exportações, mas mantêm tarifas de $16 \%$ para minimizar os efeitos negativos das políticas adotadas pelos países desenvolvidos sobre o setor lácteo doméstico. A comercialização de leite in natura e leite em pó integral predominam nas trocas entre os países do Mercosul. 
Já os países da Oceania são os que têm um maior grau de vantagens comparativas em relação às demais regiões. Com reduzidas barreiras tarifárias e sem conceder subsídios ao setor, apresentam um nível de competitividade que os torna capazes de competir com produtos europeus e americanos subsidiados.

\subsection{Cenários alternativos e efeitos dos acordos de livre comércio sobre o setor de lácteos}

O objetivo de delimitar cenários alternativos é avaliar as possíveis mudanças no mercado de lácteos mediante a implantação de políticas comerciais. Nesta seção, são avaliadas as principais alterações em termos de produção, consumo e fluxos comerciais em vista das mudanças nas barreiras tarifárias e na concessão de subsídios em relação ao período-base. Para isso, utiliza-se de um modelo de alocação espacial e vertical com o propósito de avaliar os efeitos sobre os produtos derivados do leite em cada região considerada.

A partir do cenário-base, são simulados três cenários alternativos: um acordo de livre comércio multilateral com a remoção das barreiras tarifárias e dos subsídios; um acordo Mercosul-UE com a remoção das barreiras tarifárias; e um acordo de livre comércio entre os países do Mercosul, Estados Unidos e Canadá, com a remoção das barreiras tarifárias.

Os resultados da Tabela 2 mostram como o desempenho dos produtores e o consumo de derivados nas regiões analisadas modificam quando é simulado um acordo multilateral eliminando as barreiras tarifárias e os subsídios. Nesse cenário, é possível observar os ganhos potenciais de uma situação ideal na qual os países definem as suas posições no mercado global, com base nas suas potencialidades naturais e na disponibilidade a pagar dos consumidores de cada região.

Tabela 2. Variação na produção e no consumo no cenário de livre comércio multilateral (cenário 1).

\begin{tabular}{l|r|r|r|r|r|r|r}
\hline \multirow{2}{*}{ Países } & \multirow{2}{*}{$\begin{array}{c}\text { Variação } \\
\text { produção (\%) }\end{array}$} & \multicolumn{7}{|c}{$\begin{array}{c}\text { Leite } \\
\text { fluído }\end{array}$} & $\begin{array}{c}\text { Leite em pó } \\
\text { integral }\end{array}$ & $\begin{array}{c}\text { Leite em pó } \\
\text { desnatado }\end{array}$ & Manteiga & Queijo & $\begin{array}{c}\text { Outros } \\
\text { lácteos }\end{array}$ \\
\cline { 3 - 8 } Argentina & 2.13 & -1.61 & -3.00 & -3.00 & -2.32 & -2.57 & -1.92 \\
Brasil & 1.13 & -2.65 & -6.99 & -6.98 & -0.87 & -2.68 & -3.16 \\
Uruguai & 3.13 & -1.61 & -10.11 & -10.10 & -4.86 & -2.69 & -1.93 \\
Canadá & -0.35 & 1.81 & -1.90 & -1.95 & -5.24 & -0.93 & 1.85 \\
EUA & -0.32 & 0.15 & 0.52 & 0.48 & 0.43 & 0.42 & 0.17 \\
UE & -2.61 & 1.06 & 5.36 & 5.36 & 5.59 & 3.11 & 1.23 \\
Austrália & 1.76 & -0.72 & -1.18 & -1.17 & -1.56 & -4.91 & -0.87 \\
NZ & 1.47 & -3.72 & -11.13 & -11.13 & -1.79 & -10.92 & -4.46 \\
RM & 0.38 & -0.95 & -1.76 & -1.76 & -1.51 & -2.26 & -1.12 \\
\hline
\end{tabular}

Fonte: Resultados de pesquisa. 
Os produtores de leite dos países do Mercosul são beneficiados no cenário 1 (C1), dado o importante aumento no volume produzido. Contudo, na medida em que a produção cresce para atender a uma maior demanda internacional por derivados de leite, os preços domésticos também sobem, afetando negativamente o consumo nos países do Mercosul. A Argentina e o Uruguai são exportadores líquidos, com seus produtores sendo beneficiados com mais intensidade que os brasileiros. Isso ocorre pelo fato de o Brasil ser um importador líquido no cenário-base e, nos cenários alternativos de liberalização dos mercados, as exportações argentinas e uruguaias - outrora direcionadas para o Brasil-, serem redirecionadas para outros mercados.

Os produtores dos EUA, Canadá e dos países da UE têm a sua produção reduzida em função da abertura dos seus mercados e da eliminação dos subsídios concedidos a eles e a exportadores. As regiões produtoras mais afetadas são a UE e os EUA, com quedas de 2,6\% e 0,3\%, respectivamente. Embora ocorram perdas para os produtores, existe, ao mesmo tempo, um aumento no consumo de leite e derivados com a importação de produtos mais baratos, principalmente, dos países da Oceania.

No cenário 1, é possível observar que a produção nos países da Oceania aumenta de forma significativa. Esse comportamento está associado a uma forte redução no consumo de lácteos nesses países. O consumo de leite em pó (integral e desnatado) e queijo diminui cerca de 10\% neste cenário, levando ao incremento das exportações.

Ainda no cenário 1, pode-se analisar as variações nos ganhos ou perdas quando simuladas mudanças nas elasticidade de oferta e de demanda. Conforme as Figuras 3 e 4, simulou-se um aumento de $30 \%$ na oferta e na demanda (C1S +30 e C1D +30, respectivamente) e uma diminuição de $30 \%$ na oferta e na demanda (C1S-30 e C1D-30, nesta ordem).

No cenário de livre comércio (C1), os países do Mercosul mantêm ganhos positivos na produção, exceto nas simulações em que existem um aumento da elasticidade de demanda $(\mathrm{C} 1 \mathrm{D}+30)$ e uma redução da elasticidade de oferta (C1S-30). No caso de aumentar a elasticidade de demanda, ${ }^{3}$ Argentina, Brasil e Uruguai passariam a ter perdas na produção de $2,1 \%, 1,1 \%$ e $3 \%$, respectivamente. Já para os EUA e UE, as quedas seriam ainda mais acentuadas que no C1, de 9,7\% e 6,2\%, nesta ordem. Para uma redução na elasticidade de oferta $^{4}(\mathrm{C} 1 \mathrm{~S}+30)$, Argentina, Brasil, Uruguai, EUA e UE passam a ter perdas de $1,1 \%, 0,7 \%, 1,6 \%, 7,2 \%$ e $5,2 \%$, respectivamente (Figura 3).

3 A elasticidade de demanda pode ter variações nos países analisados em relação ao cenário-base caso haja mudanças na renda, produtos substitutos, na essencialidade do bem ou, simplesmente, na preferência dos consumidores.

4 A elasticidade de oferta pode ter variações caso haja mudanças tecnológicas na produção e/ou comercialização, novas alternativas na produção, entre outros aspectos. Produtos com maior elasticidade são mais sensíveis a variações nos preços e vice-versa. 
Figura 3. Análise de sensibilidade da produção de leite no cenário 1 para mudanças nas elasticidades $(\%)$.

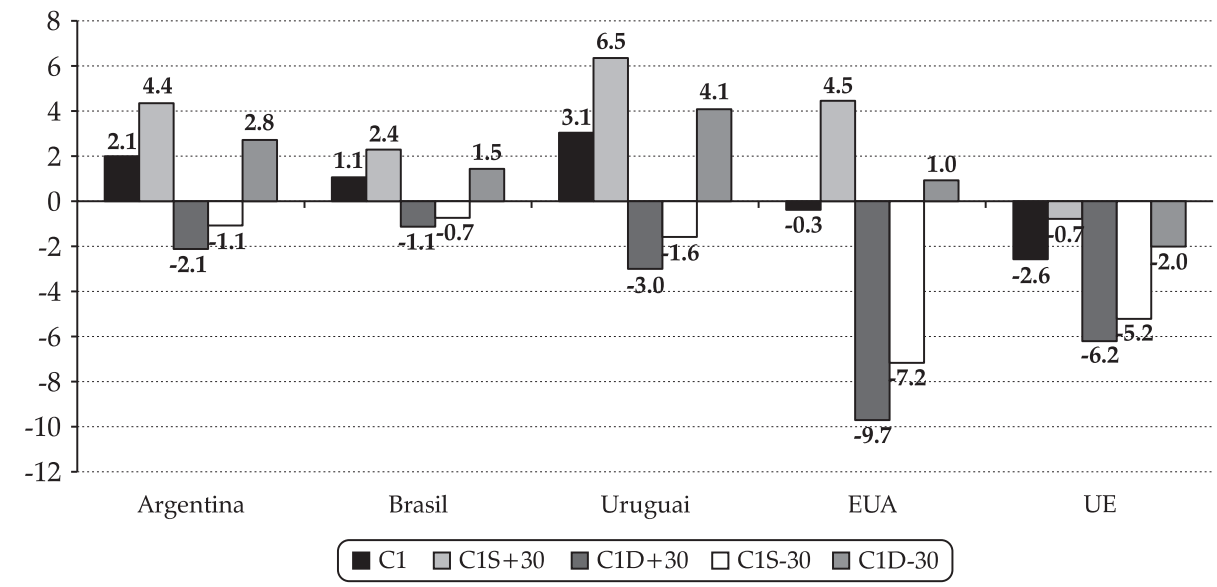

Fonte: Resultados de pesquisa.

Figura 4. Análise de sensibilidade do consumo de leite no cenário 1 para mudanças nas elasticidades (\%).

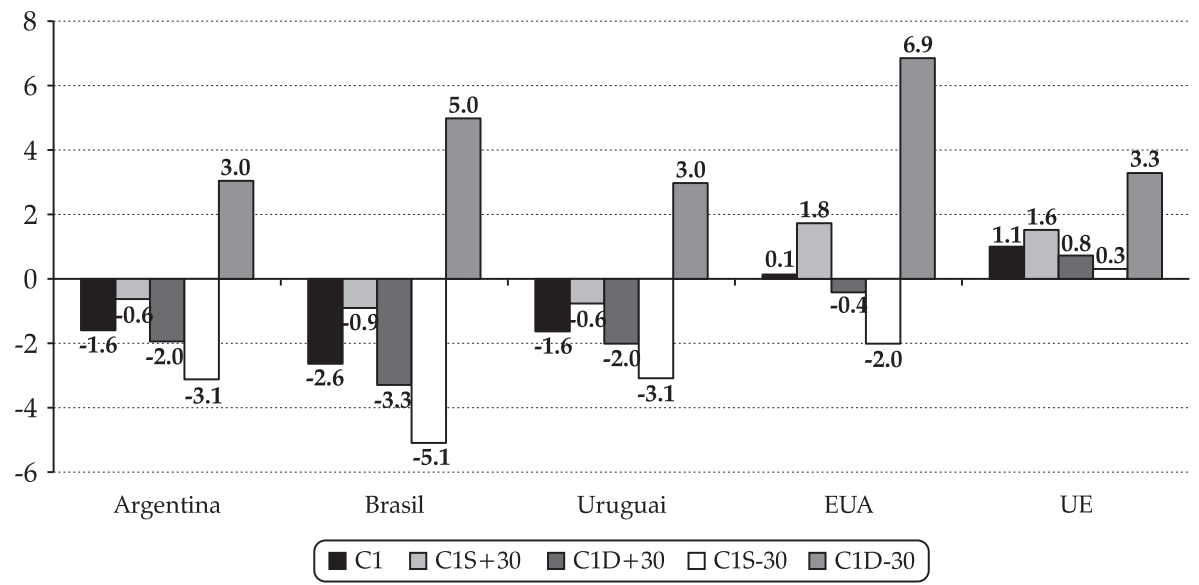

Fonte: Resultados de pesquisa.

Quando realizada a mesma análise de sensibilidade para o consumo de leite no C1 (Figura 4) nos países do Mercosul, observa-se que, com exceção do cenário de redução da elasticidade de demanda, todos os demais simulados apresentam perdas para os consumidores. O cenário que prevê a queda na elasticidade de demanda torna possível que todas as regiões selecionadas registrem ganhos para os consumidores. 
Já no cenário 2 (C2), no qual é simulado o acordo de livre comércio entre os países da UE e do Mercosul, as variações na produção e no consumo de lácteos ocorrem com maior intensidade nos países da UE e do Mercosul, participantes do bloco e nos países da Oceania (Tabela 3).

Tabela 3. Variação na produção e no consumo entre os países do Mercosul e da UE (cenário 2).

\begin{tabular}{l|r|r|r|r|r|r|r}
\hline \multirow{2}{*}{ Países } & \multirow{2}{*}{$\begin{array}{c}\text { Variação } \\
\text { produçáo (\%) }\end{array}$} & \multicolumn{7}{|c}{$\begin{array}{c}\text { Leite } \\
\text { fluído }\end{array}$} & $\begin{array}{c}\text { Leite em pó } \\
\text { integral }\end{array}$ & $\begin{array}{c}\text { Leite em pó } \\
\text { desnatado }\end{array}$ & Manteiga & Queijo & $\begin{array}{c}\text { Outros } \\
\text { lácteos }\end{array}$ \\
\hline Argentina & 4.36 & -3.27 & -5.84 & -5.81 & -1.63 & -4.79 & -3.86 \\
\hline Brasil & 2.31 & -5.37 & -12.88 & -12.79 & -0.49 & -4.53 & -6.31 \\
\hline Uruguai & 6.44 & -3.27 & -18.97 & -18.86 & -3.39 & -5.00 & -3.86 \\
\hline Canadá & 0.00 & 0.00 & 0.00 & 0.00 & 0.00 & 0.00 & 0.00 \\
\hline EUA & 0.00 & 0.00 & 0.00 & 0.00 & 0.00 & 0.00 & 0.00 \\
\hline UE & -0.27 & 0.11 & 1.09 & 1.07 & 0.55 & 0.31 & 0.12 \\
\hline Austrália & -0.31 & 0.13 & 0.21 & 0.21 & 0.28 & 0.89 & 0.16 \\
\hline NZ & -0.25 & 0.65 & 2.07 & 2.06 & 0.31 & 1.99 & 0.80 \\
RM & -0.14 & 0.34 & 0.64 & 0.64 & 0.36 & 0.82 & 0.41 \\
\hline
\end{tabular}

Fonte: Resultados de pesquisa.

Neste cenário (C2), apesar de apenas as barreiras tarifárias terem sido eliminadas, a produção e as exportações de derivados de leite dos países do Mercosul aumentaram de forma mais intensa que no $\mathrm{C} 1$. O consumo de leite e derivados, à semelhança do cenário 1 , teve redução significativa nos três países do Mercosul, chegando a $20 \%$ no Uruguai e a $13 \%$ no Brasil, no caso da demanda por leite em pó.

Por outro lado, a queda na produção de leite na UE é pequena $(0,27 \%)$, assim como as variações positivas no consumo de leite e derivados. Uma das explicações é o fato de este cenário considerar somente a eliminação das barreiras tarifárias, mantendo os subsídios numa região que representa $25 \%$ da produção mundial em equivalente leite.

A redução na produção de lácteos dos países da Oceania ocorreu em função do desvio de comércio que o C2 determina à Austrália e à Nova Zelândia. Tradicionais exportadores de lácteos à UE, têm parte do seu acesso comprometido pelo fato de este acordo comercial dar preferência às importações de lácteos dos países do Mercosul.

Quando simuladas variações na elasticidade de oferta e de demanda no C2 para a produção de leite, observa-se que, para os países do Mercosul, existem ganhos em todas as situações consideradas (Figura 5). Quando incrementada a elasticidade de oferta em $30 \%$, o cenário 2 mostra-se o mais favorável - os ganhos para a Argentina, Brasil e Uruguai são de 6,4\%,3,5\% e 9,5\%, respectivamente. São também observados aumentos de produção para os países da UE e para os EUA no cenário C2S+30, embora os EUA não façam parte do acordo. 
Figura 5. Análise de sensibilidade da produção de leite no cenário 2 para mudanças nas elasticidades (\%).

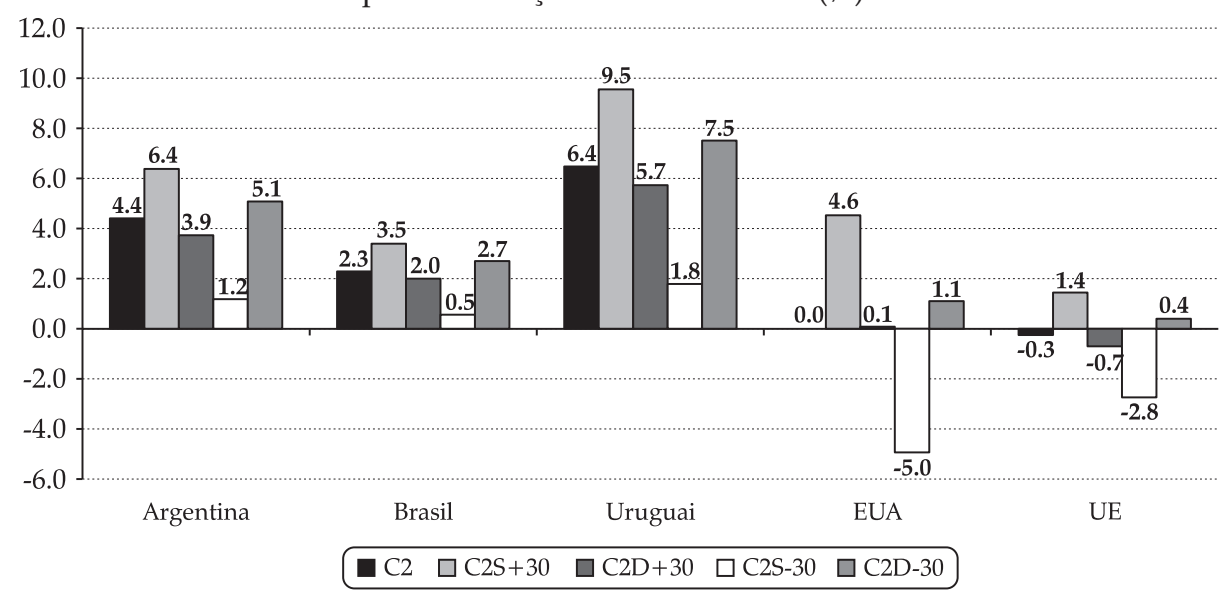

Fonte: Resultados de pesquisa.

Já para o consumo de leite nos países do Mercosul é possível observar, a partir das simulações de variações nas elasticidades de demanda e de oferta, que existem perdas à semelhança do registrado no cenário 1. As maiores quedas ocorrem quando a elasticidade de demanda aumenta em 30\% (C2D+30), chegando a $5,4 \%$ para os consumidores argentinos, a $8,7 \%$ para os brasileiros e a 5,4\% para os uruguaios (Figura 6).

Figura 6. Análise de sensibilidade do consumo de leite no cenário 2 para mudanças nas elasticidades $(\%)$.

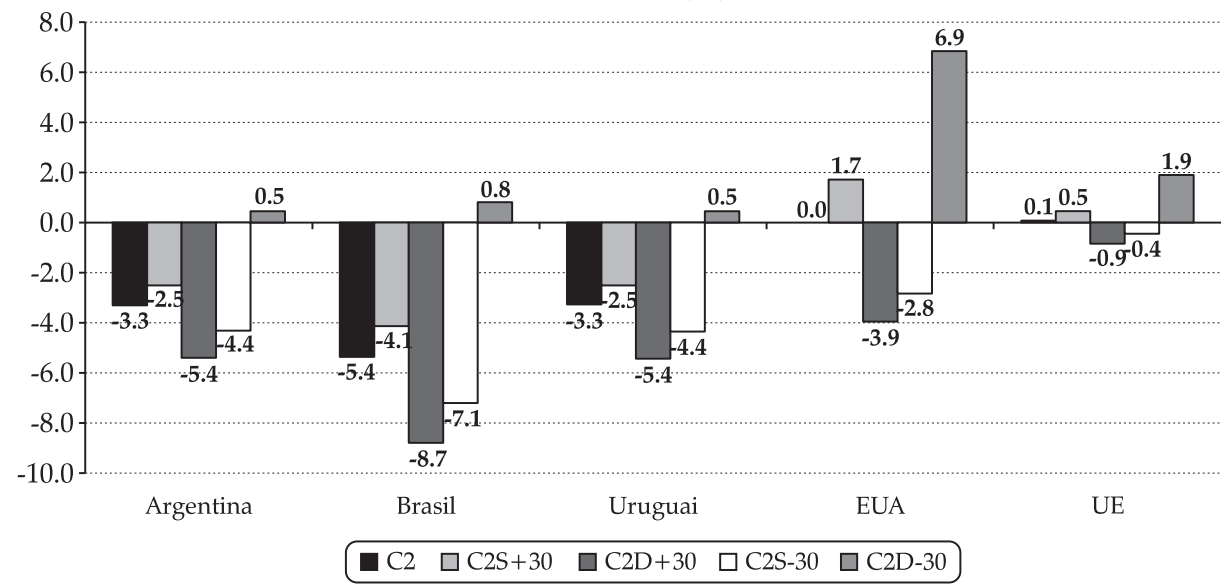

Fonte: Resultados de pesquisa. 
No caso da UE e dos EUA, o cenário 2 praticamente não tem o consumo afetado pelo acordo. Já com o aumento da elasticidade de oferta $(\mathrm{C} 2 \mathrm{~S}+30)$ e a redução da elasticidade de demanda (C2D-30), notam-se ganhos para os consumidores.

De forma geral, para os países do Mercosul, a simulação do acordo MercosulUE sinaliza ganhos para os produtores de leite e perdas para os consumidores, independente da elasticidade de oferta e demanda considerada.

Os resultados apresentados na Tabela 4 destacam as variações na produção e no consumo de leite e derivados a partir da simulação da formação de uma área de livre comércio entre os países do Mercosul, EUA e Canadá (cenário 3 ou C3). Ao contrário do cenário anterior, no C3, as variações na produção e no consumo afetam todas as regiões analisadas.

Apenas os países do Mercosul registram variações positivas na produção de leite. Como nos cenários anteriores, Argentina e Uruguai obtiveram os maiores incrementos, de $1,5 \%$ e $2,2 \%$, respectivamente. Os demais países envolvidos no acordo (EUA e Canadá) apresentaram pequenas perdas, visto que apenas as tarifas foram eliminadas. Da mesma forma, todos os outros países considerados no estudo tiveram a produção reduzida, em função do desvio de comércio resultante da formação da área de livre comércio. Nesse caso, incluem-se os países da Oceania e da UE que, no cenário-base, exportam produtos lácteos para o Canadá e EUA.

Tabela 4. Variação na produção e no consumo entre Mercosul,

EUA e Canadá (cenário 3).

\begin{tabular}{l|r|r|r|r|r|r|r}
\hline \multirow{2}{*}{ Países } & \multirow{2}{*}{$\begin{array}{c}\text { Variação } \\
\text { produção (\%) }\end{array}$} & \multicolumn{7}{|c}{$\begin{array}{c}\text { Leite } \\
\text { fluído }\end{array}$} & $\begin{array}{c}\text { Leite em pó } \\
\text { integral }\end{array}$ & $\begin{array}{c}\text { Leite em pó } \\
\text { desnatado }\end{array}$ & Manteiga & Queijo & $\begin{array}{c}\text { Outros } \\
\text { lácteos }\end{array}$ \\
\hline Argentina & 1.52 & -1.15 & -2.16 & -2.16 & -1.15 & -1.85 & -1.39 \\
Brasil & 0.79 & -1.86 & -4.89 & -4.80 & -0.33 & -1.89 & -2.24 \\
Uruguai & 2.22 & -1.15 & -7.33 & -7.32 & -2.42 & -1.94 & -1.38 \\
Canadán & 0.00 & 0.08 & 0.17 & 0.17 & 0.27 & 0.13 & 0.10 \\
EUA & -0.20 & 0.09 & 2.65 & 2.61 & 1.58 & 0.27 & 0.11 \\
UE & -0.06 & 0.02 & 0.11 & 0.11 & 0.12 & 0.07 & 0.03 \\
Austrália & -0.07 & 0.03 & 0.04 & 0.04 & 0.06 & 0.19 & 0.03 \\
NZ & -0.05 & 0.14 & 0.44 & 0.43 & 0.06 & 0.41 & 0.17 \\
RM & -0.03 & 0.07 & 0.13 & 0.13 & 0.07 & 0.17 & 0.08 \\
\hline
\end{tabular}

Fonte: Resultados de pesquisa.

No cenário de formação de área de livre comércio entre os países do Mercosul, da UE e os EUA, existem ganhos para os produtores do Mercosul no C3 mesmo quando a elasticidade de demanda e de oferta tem seus valores aumentados em 30\% (Figura 7). 
Figura 7. Análise de sensibilidade da produção de leite no cenário 3 para mudanças nas elasticidades (\%).

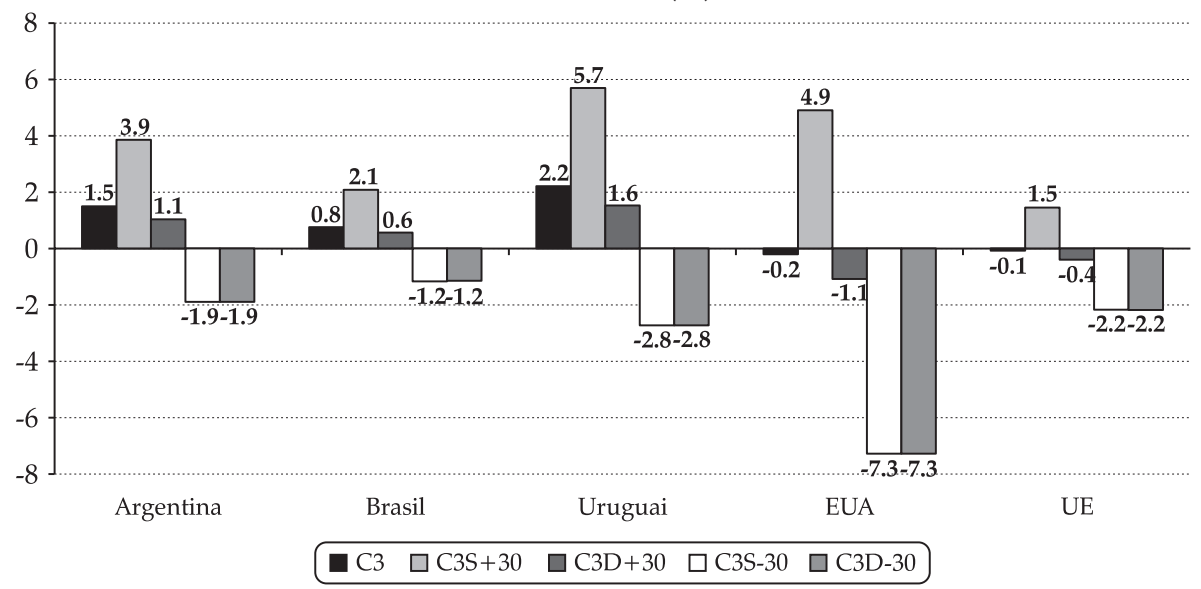

Fonte: Resultados de pesquisa.

Por outro lado, quando as elasticidades de oferta e de demanda têm seus valores reduzidos em $30 \%$, existem variações negativas na produção de leite em todos os países, em relação ao cenário-base. Para os EUA e UE, as quedas chegam a 7,3\% e 2,2\%, nesta ordem. Quando a elasticidade de oferta tem seu valor aumentado (Figura 7), constatam-se variações positivas na produção somente dos países do Mercosul.

Figura 8. Análise de sensibilidade do consumo de leite no cenário 3 para mudanças nas elasticidades $(\%)$.

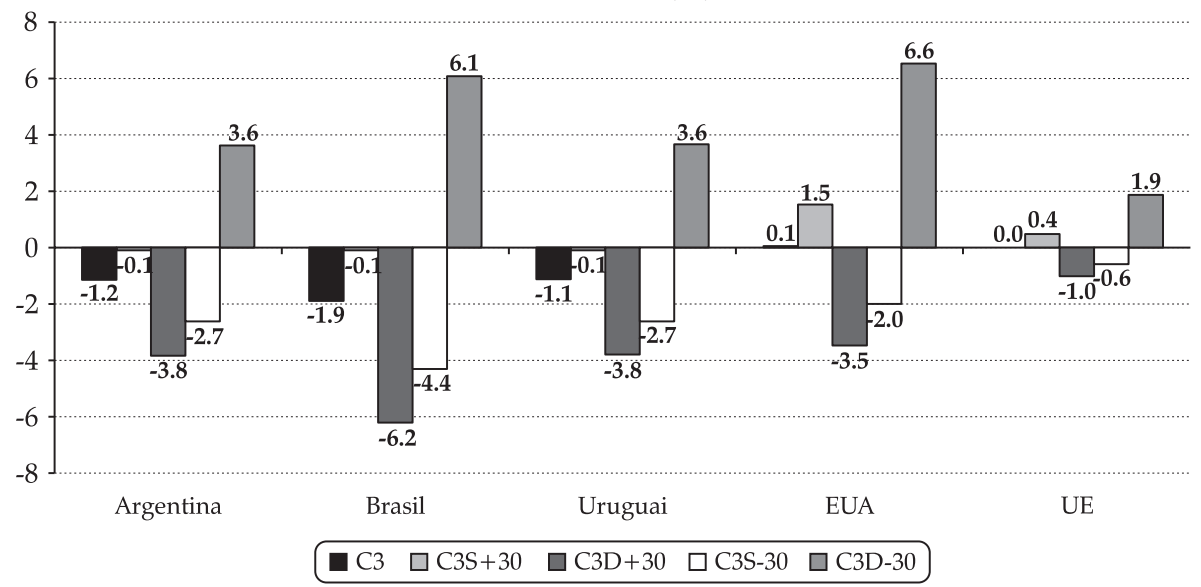

Fonte: Resultados de pesquisa. 
Analisando as possíveis variações no consumo de leite no cenário 3 frente às mudanças nas elasticidades, observa-se que, para os países do Mercosul, os impactos são negativos quando aumentam as elasticidades de oferta e de demanda ou diminui a elasticidade de oferta. Os resultados passam a ter variações positivas no consumo de lácteos apenas quando a elasticidade de demanda reduz em 30\% - os ganhos para Argentina, Brasil e Uruguai são de $3,6 \%, 6,1 \%$ e $3,1 \%$, respectivamente. Para os EUA e UE, existem variações positivas relevantes no consumo somente quando a elasticidade de oferta aumenta e a elasticidade de demanda diminui.

Em síntese, observa-se que o Brasil e os demais países do Mercosul apresentam ganhos para os produtores de leite nos três cenários considerados. O C2 é o mais promissor, ao permitir que os produtos lácteos dessas regióes tenham maior acesso ao mercado europeu, enquanto para os demais países permanecem as mesmas barreiras e restrições comerciais. Embora proporcione maiores ganhos globais, o acordo de livre comércio multilateral, no qual são eliminadas todas as restrições comerciais e os subsídios, consiste na segunda melhor opção para o Brasil e os demais países do Mercosul.

\section{Conclusões}

Este artigo compreende a análise dos efeitos dos acordos de livre comércio (multilaterais e regionais) em três cenários alternativos para o setor de lácteos. Para isso, foi utilizado um modelo de alocação espacial e vertical formulado como um Problema de Complementaridade Mista (PCM), levando em consideração nove regiões. Esse modelo permite desagregar o consumo em seis grupos: leite in natura, leite em pó integral e desnatado, manteiga, queijo e outros derivados, medindo as variações nos níveis de produção, consumo e preços-sombra em vista da remoção de barreiras ao comércio.

A partir do PCM, são avaliadas as possíveis mudanças no mercado internacional e os respectivos impactos sobre o setor de lácteos. Nesse sentido, uma das contribuições do estudo é a aplicação de uma metodologia que incorpora aspectos específicos do setor, como custos de transformação, desagregação do consumo de leite em grupos homogêneos, além da inclusão de quotas tarifárias, tarifas e subsídios para cada produto.

O modelo desenvolvido permite, ainda, incluir diferenças qualitativas do leite ao produtor (produto heterogêneo), conferindo maior robustez aos resultados, na medida em que a composição do leite é diferenciada entre as regióes analisadas. Essa ferramenta constitui-se num importante instrumental de auxílio no processo de tomada de decisão, por meio da estimação dos ganhos ou perdas em cada cenário de integração entre países ou regiões. Assim, a partir das simulações de cenários alternativos, identificam-se as melhores estratégias nas negociações internacionais que permitem ampliar a produção e a renda nos setores analisados. 
Neste estudo, apontam-se ganhos nos três cenários para produtores brasileiros de leite. O cenário mais promissor reúne os países do Mercosul e da UE através de um acordo de livre comércio no qual são eliminadas as barreiras tarifárias. Nesse cenário, apesar de o Brasil não se tornar um exportador líquido de lácteos, os produtores desse País são beneficiados pelo fato de as exportações argentinas e uruguaias serem redirecionadas para os países da UE, diminuindo o excesso de oferta nas nações do Cone Sul.

O segundo melhor cenário para os produtores brasileiros é o de livre comércio multilateral. Em termos gerais, nesse cenário existem ganhos para os países do Mercosul, da Oceania e para região denominada "resto do mundo". Para os demais países (Canadá, UE e EUA), existem reduções na produção de leite quando eliminados as tarifas e os subsídios concedidos à produção e às exportações. Já no cenário que simula um acordo de livre comércio entre os países do Mercosul, EUA e Canadá, existem ganhos para o Brasil e para os demais países do Mercosul. Todavia, nesse cenário as variações na produção foram menores para todas as nações envolvidas.

Quando comparados os resultados deste trabalho com os de outros estudos, observa-se que as estimativas obtidas se aproximam das apresentadas por Castro, Figueiredo e Teixeira (2004), que utilizaram um modelo de equilíbrio geral (GTAP) para calcular os impactos da Alca (Acordo de Livre Comércio das Américas) e do Mercosul-UE sobre um conjunto de produtos agrícolas, entre eles o leite. Para esses autores, o melhor cenário para a produção foi o Mercosul-UE. Neste artigo, contudo, as variações no volume produzido para esse acordo (MercosulUE) são menores que as registradas por Castro, Figueiredo e Teixeira (2004). Para esse estudo, os resultados apontam aumentos de $25,94 \%$ na produção de leite da Argentina, de 7,4\%, no Brasil e de 46,34\% no Uruguai.

Waquil e Alvim (2001), por meio de um modelo de equilíbrio parcial considerando apenas a dimensão espacial, avaliaram os efeitos de acordos como a Alca e o Mercosul-UE sobre o setores de lácteos e de carnes (bovina, suína e de aves). Os autores observaram que, para o setor de lácteos, o cenário mais promissor seria a Alca, no qual os países integrantes do Nafta (Estados Unidos, México e Canadá), além de Brasil e Uruguai teriam vantagens na produção.

Por fim, os resultados deste estudo apontam que acordos de caráter regional que tenham reduções tarifárias permitem melhorar as condições de mercado para os produtores brasileiros. Em outras palavras, acordos regionais como o Mercosul-UE, mesmo quando mantidos os subsídios, resultam em maiores benefícios para os produtores. 


\section{Referências Bibliográficas}

ALVIM, A. M.; WAQUIL, P. D. Impactos dos Novos Acordos de Livre Comércio sobre os Setores de Carnes e Lácteos no Brasil. Estudos do CEPE. Santa Cruz do Sul, v. 14, p. 93-109, 2001.

ALVIM, A. M. Os Impactos dos Novos Acordos de Livre Comércio sobre o Mercado de Arroz no Brasil: um modelo de alocação espacial e temporal. Porto Alegre: PPGE/ UFRGS, 2003. (Tese de Doutorado em Economia).

ALVIM, A. M.; WAQUIL, P. D. O problema de complementaridade mista: um modelo de alocação espacial aplicado ao setor agrícola. In: Santos, M. L. e Vieira, W. C. Métodos quantitativos em economia. Viçosa: UFV, 2004. Cap.6, p.161-190.

ALVIM, A. M.; WAQUIL, P. D. “O acordo entre o Mercosul e a União Européia: efeitos sobre os mercados de grãos”. In: XLIII Congresso Brasileiro de Economia e Sociologia Rural. Anais... Ribeirão Preto, SP: SOBER, 2005.

BENDER FILHO, R.; ALVIM, A. M. O Mercado de Carne Bovina no Brasil: os efeitos da eliminação das barreiras tarifárias e não tarifárias. Revista de Economia e Sociologia Rural, v. 46, p. 1095-1127, 2008.

BISHOP, P.M.; NICHOLSON, C.F; PRATT, J.E. Tariff-Rate Quotas: difficult to model or plain simple. Wellington: NZIER, 2001. Paper presented at the annual conference of the New Zealand Agricultural and Resource Economics Society. Disponível em: http://www.nzier.co.nz.

BITD (The International Customs Tariff Bureau). Tariffs Database. 2007. Disponível em: http://www.bitd.org.

CASTRO, E. R. DE.; FIGUEIREDO, A. M.; TEIXEIRA, E. C. GTAP: modelo, instruções de uso e aplicação. In: SANTOS, M.L.; VIEIRA, W.C. Métodos quantitativos em economia. Viçosa: UFV, 2004. Cap.12, p.341-374.

EMBRAPA Gado de Leite. Índice para conversão de produtos lácteos em equivalente leite de origem. 2007. Disponível em: http://www.cnpgl.embrapa.br.

FAPRI (Food and Agriculture Policy Research Center). Elasticities Databases. 2007. Disponível em: http://www.fapri.org.

FONTERRA Co-operative Group. Milk Composition. 2007. Disponível em: www. fonterra.com.

OECD/FAO (Organisation for Economic Co-operation and Development Food and Agriculture Organization of United Nations). The agricultural outlook database. Disponível em: http://www.oecd.org. 2007.

NAGURNEY, A.; NICHOLSON, C.F; BISHOP, P.M. Spatial price equilibrium models with discriminatory ad valorem tariffs: formulation and comparative computation using variational inequalities. In: VAN DEN BERGH, J.C.J.M., 
NIJKAMP, P., RIETVELD, P (eds). Recent Advances in Spatial Equilibrium Modelling: methodology and applications. New York: Springer, 1996.

NICHOLSON, C.F.; BISHOP, P. M. US Dairy Product Trade: Modeling Approaches and the Impact of New Product Formulations. Final Report for NRI Grant \# 200135400-10249, March 2004.w

RUTHEFORD, T.F. Extension of GAMS for complementarity problems arising in applied economic analysis. Journal of Economics Dynamics \& Control. n.19, p.1299$1324,1995$.

SAMUELSON, P. Spatial price equilibrium and linear programming. American Economic Review, v. 42, p. 283-303, 1952.

TAKAYAMA, T., JUDGE, G. Spatial equilibrium and quadratic programming. Journal of Farm Economics, v. 46, p. 67-93, 1964.

TAKAYAMA, T.; JUDGE, G. Spatial and temporal price and allocation models. Amsterdam/London: North-Holland Publishing Company, 1971.

THORE, S. Economic logistics: the optimization of spatial and sectoral resource, production and distribution systems. New York: Westport: London: Quorum Books, 1992.

UNCTAD (United Nation Conference on Trade and Development). UNCTAD -Trains (Trade Analysis and Information System), 2007. Disponível em: http:// www.unctad.org.

USDA (United States Departament of Agriculture). Ocean Rate Bulletin. 2007. Disponível em: http://www.ams.usda.gov.

USDA-ERS (United State Department of Agriculture - Economic Research Service). Commodity and Food Elasticities. 2007. Disponível em: http://www.ers. usda.gov/Data/Elasticities/query.aspx.

USDA-NAL (United State Departamentof Agriculture-Nutrient Data Laboratory). USDA Food Composition Data, 2007. Disponível em: http://www.nal.usda.gov.

WAQUIL, P.D. Primal-dual spatial equilibrium model with intermediate products: application to the agricultural sector in the MERCOSUR. University of Wisconsin - Madison, 1995. (Ph.D. Dissertation).

WAQUIL, P. D. Equilíbrio espacial: modelagem e aplicação ao setor de grãos em três cenários de integração regional. In: MONTOYA, A. e PARRÉ, J. L. (eds). O Agronegócio brasileiro no final do século XX. Passo Fundo: UPF, v. 2, 2000.

WORLD BANK. Ileana Cristina Neagu (ineagu@worldbank.org). cópia 24 set. 2002. E-mail para Augusto Mussi Alvim (augusto.alvim@ig.com.br). 
